\title{
Polymer-free drug-coated coronary stents are cost-effective in patients at high bleeding risk: economic evaluation of the LEADERS FREE trial
}

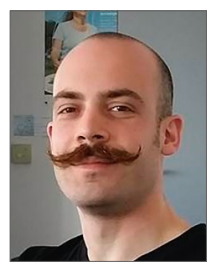

\author{
Antoine Filipovic-Pierucci ${ }^{*}$, MD, MPH; Isabelle Durand-Zaleski ${ }^{1,2,3}, \mathrm{MD}, \mathrm{PhD}$; \\ Thibault Butel ${ }^{1}$, MD, MPH; Samantha Greene ${ }^{4}$, BA; Thomas Hovasse 5 , MD; \\ Andres Iñiguez ${ }^{6}, \mathrm{MD}, \mathrm{PhD}, \mathrm{FESC}$; Marco Stefano Nazzaro ${ }^{7}, \mathrm{MD}, \mathrm{PhD}$; \\ Keith G. Oldroyd ${ }^{8}, \mathrm{MBChB}$, MD; Suneel Talwar ${ }^{9}, \mathrm{MBBS}, \mathrm{MRCP}, \mathrm{MD}$; Gert Richardt ${ }^{10}, \mathrm{MD}$; \\ Ute Windhovel ${ }^{11}$, PhD; Philip Urban ${ }^{12}$, MD; Marie-Claude Morices, MD; \\ for the LEADERS FREE investigators
}

1. Assistance Publique Hopitaux de Paris, URC Eco \& Santé Publique, Hôpital Henri Mondor, Créteil, France; 2. Université Paris Est Créteil, Créteil, France; 3. INSERM ECEVE UMR 1123, Paris, France; 4. Biosensors, Morges, Switzerland; 5. Hôpital Privé Jacques Cartier, Massy, France; 6. Hospital Alvaro Cunqueiro (Complejo Hospitalario Universitario de Vigo), Vigo, Spain; 7. Azienda Ospedaliera San Camillo Forlanini, Rome, Italy; 8. West of Scotland Regional Heart \& Lung Centre, Golden Jubilee National Hospital, Glasgow, United Kingdom; 9. Dorset Heart Centre, Royal Bournemouth Hospital, Bournemouth, United Kingdom; 10. Herzzentrum, Segeberger Kliniken GmbH, Bad Segeberg, Germany; 11. CERC, Massy, France; 12. Hôpital de la Tour, Geneva, Switzerland

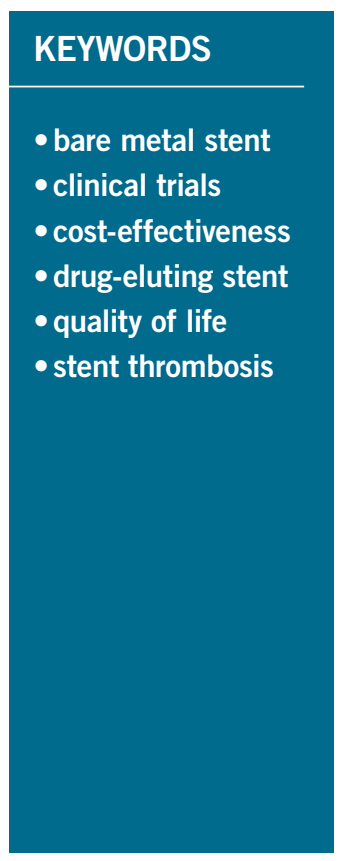

\begin{abstract}
Aims: In patients at high risk of bleeding who undergo PCI, the Biolimus A9 polymer-free drug-coated stent (DCS) has superior efficacy and safety compared to a bare metal stent (BMS). We estimated the costeffectiveness of DCS vs. BMS.

Methods and results: The LEADERS FREE-based economic evaluation estimated service use and quality of life data collected prospectively. The entire trial population was analysed using cost weights from England, France, Germany, Italy, Scotland and Spain. Country-specific QALYs were derived from EQ-5D scores. We estimated cost per event averted and per QALY gained. DCS use resulted in -0.095 cardiac deaths, target vessel MI, stent thrombosis and revascularisation per patient $(0.152$ vs. $0.237 ; \mathrm{p}<0.001)$. One-year QALYs were non-significantly higher in the DCS group. Total costs for the index admission were similar among groups. One-year costs using cost weights from each of the six countries, including the additional $€ 300$ per DCS stent, ranged from $€ 4,664-8,593$ for DCS and $€ 4,845-9,742$ for BMS and were lower in the DCS group (England: $-428 €$, France: $-137 €$, Germany: $-33 €$, Italy: $-522 €$, Scotland: $-298 €$, Spain: $-854 €)$.
\end{abstract}

Conclusions: The probability that DCS dominated BMS was $>50 \%$ in all countries. At a threshold of $€ 10,000$ per event averted, DCS had a $98 \%$ probability of being cost-effective in all six countries.

\footnotetext{
*Corresponding author: URC Eco Hotel Dieu, 1 Place du Parvis de Notre-Dame, 75004 Paris, France. E-mail: antoine.filipovic-pierucci@urc-eco.fr
} 


$\begin{array}{ll}\text { Abbreviations } \\ \text { BMS } & \text { bare metal stent } \\ \text { CHEERS } & \text { Consolidated Health Economic Evaluation Reporting } \\ & \text { Standards } \\ \text { DAPT } & \text { dual antiplatelet therapy } \\ \text { DCS } & \text { drug-coated stent } \\ \text { MACE } & \text { major adverse cardiac events } \\ \text { PCI } & \text { percutaneous coronary intervention } \\ \text { QALY } & \text { quality-adjusted life-years }\end{array}$

\section{Introduction}

The choice of drug-coated stents vs. bare metal stents for patients undergoing percutaneous revascularisation is based upon medical criteria but also has economic implications due to the large number of patients receiving stents worldwide. In populations that are not at increased risk of bleeding, drug-eluting stents were found to be cost-effective compared to bare metal stents in patients at high risk of cardiac events ${ }^{1}$. At least $15 \%$ of patients who undergo percutaneous coronary intervention (PCI) are at increased risk of bleeding ${ }^{2,3}$, at a cost of US $\$ 4,000-14,000$ per episode 4 . Due to their relative or absolute contraindication to prolonged dual antiplatelet therapy (DAPT), these patients at high risk of bleeding are often treated with bare metal stents followed by one month of DAPT only ${ }^{5,6}$, which is associated with a higher risk of restenosis and reintervention than that observed with the use of a drug-eluting stent ${ }^{7}$. LEADERS FREE was a double-blind multicentre trial including nearly 2,500 patients at high risk of bleeding comparing BioFreedom $^{\mathrm{TM}}$ (Biosensors Europe, Morges, Switzerland), a new Biolimus A9 polymer-free drug-coated stent, to a bare metal stent. The Biolimus A9 drug-coated stent demonstrated superiority at one year in terms of both safety (composite endpoint of death, MI and stent thrombosis of $9.4 \%$ vs. $12.9 \%, \mathrm{p}<0.005$ ) and efficacy (clinically indicated target lesion revascularisation of $5.1 \%$ vs. $9.8 \%, \mathrm{p}<0.001$ ), all patients being treated with one month only of DAPT followed by single antiplatelet treatment ${ }^{8}$.

We performed a prospective health economic evaluation alongside the LEADERS FREE trial to understand the cost-effectiveness of these alternative stenting strategies.

\section{Methods}

\section{STUDY DESIGN AND ORGANISATION}

The design and results of the LEADERS FREE trial have been described previously ${ }^{8}$. Between December 2012 and May 2014, 2,466 patients at increased bleeding risk underwent randomisation to treatment with a Biolimus A9 (BA9) coated stent or a bare metal stent. The prospective economic evaluation was concurrent with the randomised trial, in accordance with the CHEERS guidelines 9 . The perspective chosen was that of the healthcare system; resources and quality of life were collected prospectively alongside the clinical trial. Study participants lost to follow-up were included in the analysis. LEADERS FREE was conducted at 68 sites in 20 countries on four continents. The cost weights used in the economic analysis were obtained from countries where the number of patients included allowed precise estimates of country-specific values (England, France, Germany, Italy, Scotland and Spain). We analysed the overall trial population using cost weights from each of the six countries mentioned ${ }^{10-12}$. LEADERS FREE ClinicalTrials.gov number: NCT01623180.

\section{EFFECTIVENESS}

The economic evaluation used components of the safety and efficacy endpoints (cardiac death, target vessel myocardial infarction, target vessel stent thrombosis and target lesion revascularisation) and quality-adjusted life-years (QALY). The use of clinical endpoints as effectiveness criteria is standard in economic evaluations of cardiac interventions ${ }^{1,11}$, and the use of QALY is recommended by the CHEERS guidelines 9 . Because the clinical study found homogeneity of safety and efficacy between study locations, we pooled the one-year clinical results from all countries ${ }^{8}$.

\section{ESTIMATION OF RESOURCE UTILISATION}

All costs were assessed from the perspective of the healthcare system. The time horizon was one year. We verified practice heterogeneity between countries to ensure that medical resource utilisation could be pooled for the cost analysis.

Post-procedural days for each initial hospitalisation were recorded prospectively. The follow-up cardiovascular hospitalisations were included in the economic evaluation if at least one concurrent adjudicated cardiac clinical endpoint was recorded between the day before the admission date and the discharge date.

Outpatient resources (doctor visits, medications, non-invasive exams, etc.) were not included in the cost calculations as all patients were prescribed identical scheduled follow-up in both arms and we assumed that all significant events would result in a hospital admission. For the same reason, hospitalisations for bleeding events were not counted either, as the antiplatelet therapy regimen was identical in the two groups, and bleeding events were not different between the two groups.

\section{ESTIMATION OF UNIT COSTS}

Total hospital costs were calculated as daily hospital costs multiplied by the length of stay. Either PCI or cardiac-related daily costs were applied to re-hospitalisations depending on whether a PCI procedure was performed. Costs were reported with the hospital costs of each country. Costs were reported in euros; British pounds were converted to euros using a purchasing power parity of 1.34. As stent prices vary per country, we calculated an average price mark-up of $€ 300$ for a drug-coated stent over a bare metal stent. Similar stent prices were used in all countries, as in the SYNTAX trial ${ }^{13}$.

\section{QUALITY OF LIFE}

The main outcome was expressed as QALY assessed directly from patients at baseline and at one year with the EuroQOL EQ-5D-5L questionnaire $^{14}$ health status instrument, and converted to country-specific utility weights for each studied country (UK weights 
were selected for both England and Scotland). The initial weight reflecting the quality of life at the time of the PCI was attributed to the entire month following the initial procedure. The trial did not record the EuroQOL at regular intervals during the follow-up period. We assumed that each adverse event would be associated with a utility decrement and therefore attributed the initial weight to the month following each adverse event, while the final utility weight at one year was attributed to the remaining time, except when the final utility weight was worse than at inclusion: in that case the initial weight was not used to decrement utility. Missing follow-up utilities because of premature death were imputed through linear regression prediction to the time of death. QALY were calculated for each patient as the time-weighted average of utility values.

\section{COST-EFFECTIVENESS}

A cost-effectiveness analysis was conducted to estimate incremental costs per incremental QALY for the primary analysis and clinical endpoints for the secondary analysis ${ }^{15}$. Costs and QALY were not discounted due to the short time horizon.

\section{UNCERTAINTY ANALYSIS}

Bootstrapping (10,000 replicates) was used to estimate uncertainty in the joint distribution of costs, clinical endpoints and QALY for each treatment group. Results were presented on the cost-effectiveness plane and as a cost-effectiveness acceptability curve ${ }^{16}$.

\section{STATISTICAL ANALYSIS}

Categorical data are reported as frequencies, and continuous data are reported as mean \pm SD. Discrete variables were compared by use of Fisher's exact tests. Continuous variables (including costs) were compared using bootstrap hypothesis testing in order to avoid relying on normality assumptions ${ }^{17}$. Count data were compared with a Poisson model. All analyses were performed with $\mathrm{R}$ version $3.2 .3^{18}$, and results were plotted with the ggplot2 R package ${ }^{19}$.

\section{Results}

\section{PATIENT POPULATION}

A total of 2,466 patients underwent randomisation (1,239 were assigned to the drug-coated stent and 1,227 were assigned to the bare metal stent) from December 2012 to May 2014. Of the 2,432 patients who underwent PCI, 2,385 (98.1\%) were followed until death or 390 days.

\section{EFFECTIVENESS}

In accordance with the clinical results ${ }^{8}$, the number of clinical safety and efficacy endpoints per patient was lower in the drugcoated stent group with an average reduction of 0.095 events per patient (0.152 vs. $0.237 ; \mathrm{p}<0.001)$ (Table 1$)$.

\section{UTILITY WEIGHTS AND QALY}

QALY of the one-year follow-up were non-significantly higher in the drug-coated stent group, ranging from 0.671 to 0.790 across
Table 1. Clinical endpoints (average number per patient) and utility during the 12-month follow-up period.

\begin{tabular}{|c|c|c|c|}
\hline & $\begin{array}{c}\text { Drug-coated } \\
\text { stent }\end{array}$ & $\begin{array}{l}\text { Bare metal } \\
\text { stent }\end{array}$ & $p$-value \\
\hline Endpoints & $\mathrm{N}=1,221$ & $\mathrm{~N}=1,211$ & \\
\hline CABG & 0.002 & 0.006 & 0.09 \\
\hline Cardiac death & 0.042 & 0.052 & 0.27 \\
\hline $\mathrm{MI}$ & 0.041 & 0.068 & 0.008 \\
\hline Repeat PCl & 0.053 & 0.101 & $<0.001$ \\
\hline Total endpoints & 0.152 & 0.237 & $<0.001$ \\
\hline EQ-5D-5L* (QALY) & $\mathrm{N}=984$ & $\mathrm{~N}=947$ & \\
\hline France & 0.671 & 0.662 & 0.48 \\
\hline Germany & 0.790 & 0.782 & 0.49 \\
\hline Italy & 0.723 & 0.713 & 0.42 \\
\hline Spain & 0.723 & 0.713 & 0.42 \\
\hline $\mathrm{UK}^{* *}$ & 0.693 & 0.685 & 0.47 \\
\hline \multicolumn{4}{|c|}{$\begin{array}{l}\text { * Including deceased patients for whom a zero value was attributed from } \\
\text { the time of death to the end of the follow-up period. ** England and } \\
\text { Scotland. CABG: coronary artery bypass grafting; EQ-5D-5L: EuroQOL } \\
\text { five dimensions questionnaire; MI: myocardial infarction; } \\
\text { PCI: percutaneous coronary intervention; QALY: quality-adjusted } \\
\text { life-years, using country-specific tariffs for EQ-5D-5L scores }\end{array}$} \\
\hline
\end{tabular}

countries vs. 0.662 to 0.713 for the bare metal stent group (difference from 0.008 to 0.010 ). Utilities and cumulative QALY are presented in Table 1.

\section{TREATMENT COSTS}

Resource use for the initial revascularisation procedures is summarised in Table 2. The average number of stents, angioplasty

Table 2. Resource utilisation during the initial admission and follow-up period.

\begin{tabular}{|c|c|c|c|c|}
\hline & $\begin{array}{c}\text { Drug-coated } \\
\text { stent } \\
(\mathrm{N}=1,221)\end{array}$ & $\begin{array}{c}\text { Bare metal } \\
\text { stent } \\
(\mathrm{N}=1,211)\end{array}$ & $p$-value \\
\hline \multicolumn{2}{|c|}{ Procedure admissions (N) } & 1,234 & 1,224 & \\
\hline \multicolumn{2}{|c|}{ Staged procedures (\%) } & 4.7 & 6.1 & 0.14 \\
\hline \multicolumn{2}{|c|}{ AE during initial stay (\%) } & 16.0 & 15.4 & 0.72 \\
\hline \multicolumn{2}{|c|}{$\begin{array}{l}\text { Number of stents per } \\
\text { patient }(\mathrm{m})\end{array}$} & 1.8 & 1.8 & 0.42 \\
\hline \multicolumn{2}{|c|}{ Repeat admission stays (N) } & 211 & 251 & 0.06 \\
\hline \multicolumn{2}{|c|}{$\begin{array}{l}\text { Patients with at least one } \\
\text { repeat admission (\%) }\end{array}$} & 13.7 & 16.5 & 0.065 \\
\hline \multicolumn{2}{|c|}{ Initial LOS (m days) } & 2.8 & 2.9 & 0.43 \\
\hline \multirow[t]{2}{*}{$\begin{array}{l}\text { Within } \\
\text { patients } \\
\text { with repeat } \\
\text { admission }\end{array}$} & $\begin{array}{l}\text { LOS for } \\
\text { repeat } \\
\text { admission } \\
\text { in days }(\mathrm{m})\end{array}$ & 11.9 & 15.5 & 0.27 \\
\hline & $\begin{array}{l}\text { CCU LOS } \\
\text { with repeat } \\
\text { admission } \\
\text { in days }(\mathrm{m})\end{array}$ & 4.3 & 5.0 & 0.31 \\
\hline \multicolumn{2}{|c|}{$\begin{array}{l}\text { Total average LOS for } \\
\text { index and repeat } \\
\text { admissions in days (m) }\end{array}$} & 4.4 & 5.5 & 0.056 \\
\hline
\end{tabular}


balloons and guiding wires was identical in both groups. Total procedural hospitalisation costs were similar between groups (non-significant cost differences in favour of the drug-coated stent group: England $-160 €$, France $-202 €$, Germany $-148 €$, Italy $-226 €$, Scotland $-139 €$, Spain $-295 €$ ) (Table 3). The total stent cost was higher for the drug-coated group based on an average of 1.8 stents per patient (cost difference: €557) (Table 3).

The difference in rates of cardiac death, target vessel myocardial infarction, target vessel stent thrombosis, target lesion revascularisation and length of stay was consistently in favour of the drug-coated stent group (Table 2), resulting in higher post-procedural hospital costs in the bare metal stent group in all countries (cost differences in favour of the drug-coated stent group: England $-985 €$, France $-695 €$, Germany $-591 €$, Italy $-1,079 €$, Scotland $-856 €$, Spain $-1,411 €$ ) (Table 3). The total one-year costs, including stent costs, were lower in the drugcoated stent group (cost differences: England $-588 €$, France $-339 €$, Germany $-181 €$, Italy $-748 €$, Scotland $-437 €$, Spain $-1,149 €$ ) (Table 3 ). None of these differences reached statistical significance.

\section{COST-EFFECTIVENESS AND SENSITIVITY ANALYSES}

The probability that drug-coated stents dominated bare metal stents (i.e., were both more effective and less costly) depended on the country studied and on the outcome chosen (QALY or clinical endpoints), but remained above $50 \%$ in all situations. In the QALY analysis, drug-coated stent dominance was found in: England $65 \%$, France $57 \%$, Germany $52 \%$, Italy $69 \%$, Scotland $62 \%$, and Spain $72 \%$. In the clinical events analysis, drug-coated stent dominance was found in: England 85\%, France 75\%, Germany 67\%, Italy $87 \%$, Scotland $80 \%$, and Spain $91 \%$ (Figure 1).

If stakeholders were ready to pay $€ 50,000$ per QALY, the probability of being cost-effective was $70-75 \%$ for all countries. At a threshold of $€ 10,000$ per clinical event averted, drug-coated stents had a $98 \%$ probability of being cost-effective in all countries (Figure 2).

We found that the initial admission length of stay was slightly higher for the bare metal stent group, resulting in higher hospitalisation costs for the index procedure. Since the investigators were blinded, there was no obvious clinical explanation for this non-significant difference except random fluctuation. To ensure strict comparison of effects and costs, we set the difference in post-procedural

Table 3. Stent pricing and cost, cost of the initial admission and follow-up costs.

\begin{tabular}{|c|c|c|c|c|c|}
\hline & Drug-coated stent & Bare metal stent & $\Delta$ & Cl & $p$-value \\
\hline \multicolumn{6}{|l|}{ Stent } \\
\hline Unit price difference & & & $€ 300$ & - & - \\
\hline Total cost difference ( 1.8 stents/patient) & & & $€ 557$ & $€ 519-€ 595$ & $<0.001$ \\
\hline \multicolumn{6}{|l|}{ England } \\
\hline Index procedure & $€ 2,614$ & $€ 2,774$ & $-160 €$ & $-515 €-191 €$ & 0.36 \\
\hline Repeat admission & $€ 1,750$ & $€ 2,735$ & $-985 €$ & $-2,126 €--37 €$ & $0.060 *$ \\
\hline Net cost & $€ 5,350$ & $€ 5,938$ & $-588 €$ & $-1,803 €-463 €$ & 0.30 \\
\hline \multicolumn{6}{|l|}{ France } \\
\hline Index procedure & $€ 3,292$ & $€ 3,493$ & $-202 €$ & $-649 €-241 €$ & 0.36 \\
\hline Repeat admission & $€ 1,603$ & $€ 2,298$ & $-695 €$ & $-1,605 €-84 €$ & 0.10 \\
\hline Net cost & $€ 5,882$ & $€ 6,221$ & $-339 €$ & $-1,382 €-608 €$ & 0.50 \\
\hline \multicolumn{6}{|l|}{ Germany } \\
\hline Index procedure & $€ 2,412$ & $€ 2,560$ & $-148 €$ & $-476 €-176 €$ & 0.36 \\
\hline Repeat admission & $€ 1,264$ & $€ 1,855$ & $-591 €$ & $-1,335 €-41 €$ & 0.088 \\
\hline Net cost & $€ 4,664$ & $€ 4,845$ & $-181 €$ & $-1,015 €-570 €$ & 0.64 \\
\hline \multicolumn{6}{|l|}{ Italy } \\
\hline Index procedure & $€ 3,689$ & $€ 3,915$ & $-226 €$ & $-727 €-270 €$ & 0.36 \\
\hline Repeat admission & $€ 2,127$ & $€ 3,207$ & $-1,079 €$ & $-2,383 €-23 €$ & 0.075 \\
\hline Net cost & $€ 6,804$ & $€ 7,551$ & $-748 €$ & $-2,180 €-512 €$ & 0.27 \\
\hline \multicolumn{6}{|l|}{ Spain } \\
\hline Index procedure & $€ 4,824$ & $€ 5,120$ & $-295 €$ & $-951 €-353 €$ & 0.36 \\
\hline Repeat admission & $€ 2,782$ & $€ 4,193$ & $-1,411 €$ & $-3,116 €-30 €$ & 0.075 \\
\hline Net cost & $€ 8,593$ & $€ 9,742$ & $-1,149 €$ & $-3,017 €-496 €$ & 0.19 \\
\hline \multicolumn{6}{|l|}{ Scotland } \\
\hline Index procedure & $€ 2,270$ & $€ 2,409$ & $-139 €$ & $-448 €-166 €$ & 0.36 \\
\hline Repeat admission & $€ 1,520$ & $€ 2,376$ & $-856 €$ & $-1,847 €--32 €$ & $0.060 *$ \\
\hline Net cost & $€ 4,777$ & $€ 5,215$ & $-437 €$ & $-1,494 €-477 €$ & 0.38 \\
\hline
\end{tabular}




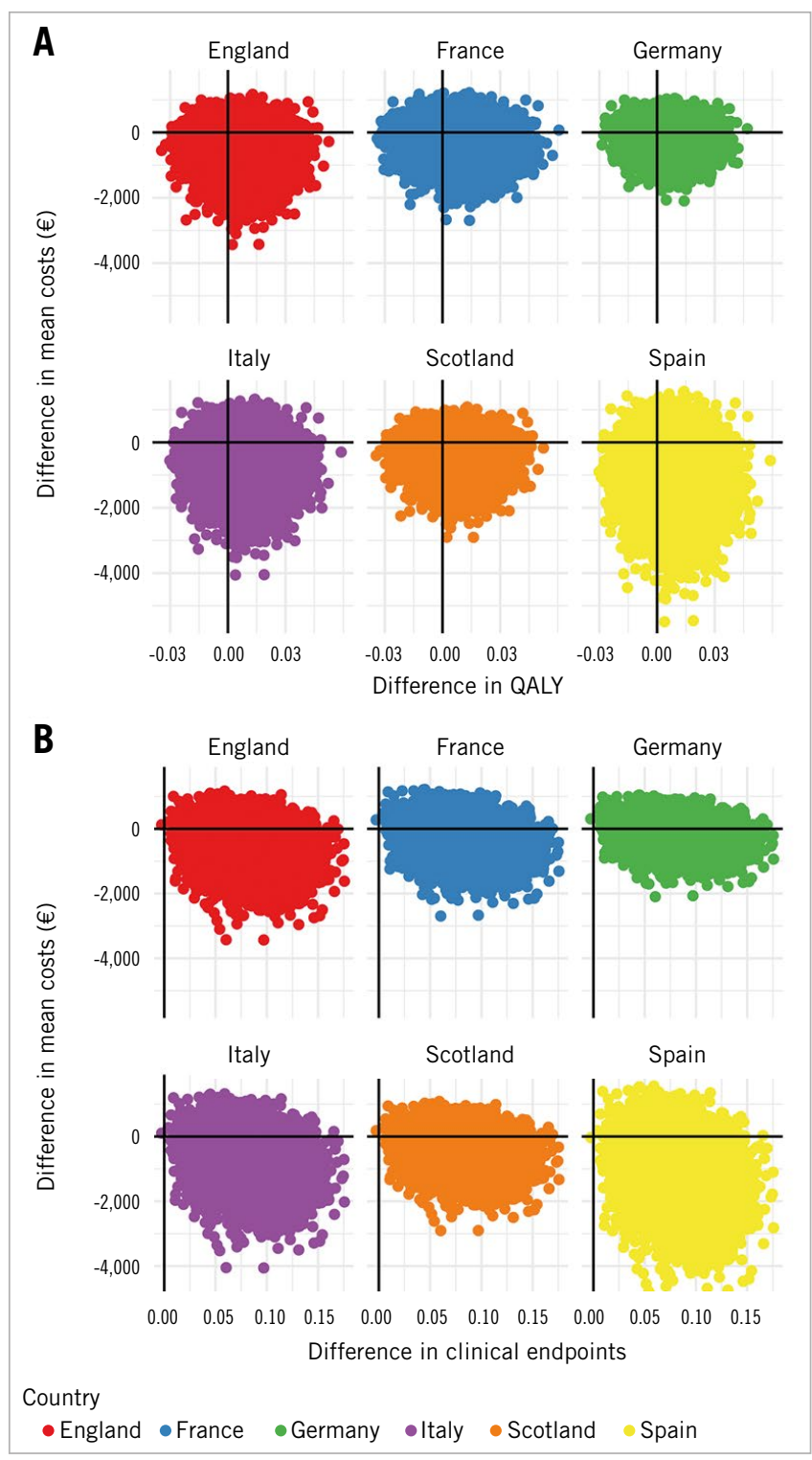

Figure 1. Distribution of the incremental cost and effectiveness on the cost-effectiveness plane. Distribution obtained by bootstrapping on the cost-effectiveness plane for QALY (A) and clinical endpoints (B) representing the incremental effectiveness of drug-coated stents over bare metal stents on the $X$-axis, and the incremental cost on the Y-axis.

costs at $€ 0$ and found that the results of the economic evaluation remained similar (England: $-428 €$, France: $-137 €$, Germany: $-33 €$, Italy: $-522 €$, Scotland: $-298 €$, Spain: $-854 €)$.

\section{Discussion}

LEADERS FREE was the first study to compare directly the clinical and economic outcomes of drug-coated and bare metal stents in patients at high risk of bleeding. Use of the drug-coated stent was associated with a better safety and reduced events rate at one year. This economic substudy provides information on the efficient stenting strategy in such patients. The average total one-year cost of drug-coated stent patients was consistently lower than the
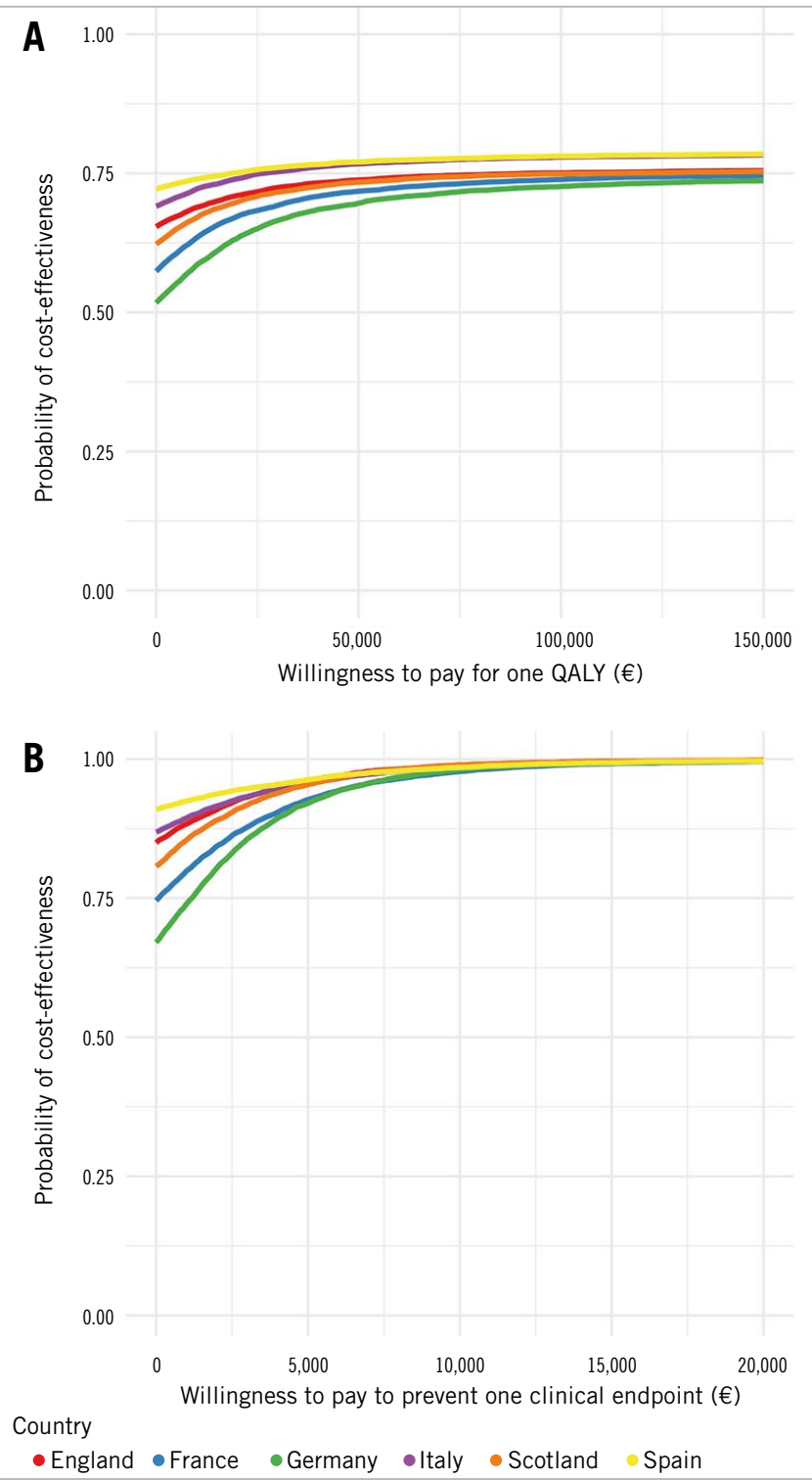

Figure 2. Cost-effectiveness acceptability curve: probability of cost-effectiveness in relation to willingness to pay. Probability of drug-coated stents being more cost-effective than bare metal stents on the Y-axis, depending on the stakeholder's willingness to pay for $Q A L Y(A)$ or an improvement in clinical endpoints $(B)$ on the X-axis.

cost of bare metal stent patients, making the drug-coated intervention cost-saving. Overall, using cost weights from each of the six countries studied, we found that the drug-coated stent dominated the bare metal stent despite higher initial stent costs.

This dominance of drug-coated stents was explained by the better results in safety and efficacy: hospital costs were reduced in all countries following fewer and shorter re-admissions, and lower costs. Between-country variations were mostly explained by differences in hospital costs; higher hospital costs were associated with a higher probability of drug-coated stents being dominant. Results were less striking for QALY than for clinical endpoint prevention due to the low sensitivity of the EQ-5D-5L to detect 
quality-of-life improvements in coronary patients over a oneyear period. These results are in line with the NORSTENT study (with a five-year follow-up) that did not find significant differences in QALY while the rate of repeat revascularisation differed between groups $^{20}$.

The LEADERS FREE clinical trial found the drug-coated stent to be significantly superior in terms of safety (composite endpoint of death, MI and stent thrombosis of $9.4 \%$ vs. $12.9 \%, \mathrm{p}<0.005$ ) and efficacy (clinically indicated target lesion revascularisation of $5.1 \%$ vs. $9.8 \%, \mathrm{p}<0.001$ ), while the difference in hospital admissions for clinical events during that same period did not reach statistical significance. This is explained by the fact that several adverse events resulted in only one admission (e.g., stent thrombosis and PCI) that reduced the $10 \%$ difference in total clinical endpoints to a $3 \%$ difference in total re-admissions (Table 1, Table 2). Total costs were mainly driven by the costs of the initial procedure (hospital stay and stent cost); the cost of repeat admissions represented on average $1 / 4$ to $1 / 3$ of total one-year costs. Thus, the difference in one-year costs was not proportional to the difference in clinical effects.

Cost-effectiveness ratios reported in the BASKET trial were $€ 64,732$ to prevent one major adverse cardiac event, and $€ 40,467$ per QALY gained, higher than our results where drug-coated stents were more effective and less costly. However, in the subgroup of high-risk patients, the efficiency was very much improved. Our findings are consistent with other studies that showed costeffectiveness ratios driven by stent prices and their number ${ }^{1,21,22}$. LEADERS FREE reported about the same number of stents per lesion as the BASKET trial ${ }^{1}$, while other trials had fewer stents per patient ${ }^{23,24}$.

Economic evaluations of drug-eluting stents versus bare metal stents consistently showed that the former are more effective in reducing major adverse cardiac events (MACE) and also more costly. In the SIRIUS trial, the base-case analysis found an incremental cost-effectiveness ratio for sirolimus-eluting stenting at US $\$ 1,650$ per repeat revascularisation avoided, a cost utility of US $\$ 27,540$ per QALY gained, <US $\$ 50,000$ per QALY in $63.2 \%$ and $<$ US $\$ 100,000$ per QALY in $87.1 \%$ of bootstrap simulations ${ }^{24}$. The initial costs of the drug-eluting stents can be offset in part when the follow-up period is long. A model-based economic evaluation of the Endeavor ${ }^{\circledR}$ drug-eluting stent vs. the Driver ${ }^{\circledR}$ bare metal stent (both Medtronic, Minneapolis, MN, USA) over a fouryear time period found an incremental cost-effectiveness ratio of $£ 3,757 / \mathrm{QALY}^{25}$.

Our decision to pool results for efficacy and resource use but to separate resource costs per country is in line with findings that the factor most frequently cited as generating variability in economic results between locations was the unit costs associated with particular resources ${ }^{26}$.

\section{Limitations}

Repeat admissions were selected to be included in the cost analysis when they occurred at the same date as a cardiac event described as safety or efficacy endpoints in the trial data. We did not use the hospitals' discharge data principal diagnoses because: 1) the coding rules of principal diagnoses differ between countries, and 2) principal diagnoses are sometimes coded according to economic rather than clinical criteria. We used the same mark-up in stent price for all countries because the exact per-country prices were not disclosed by the manufacturers for confidentiality reasons.

\section{Conclusions}

Taking into account the country level differences in hospital costs, we found that using Biolimus A9 drug-coated stents in patients at high bleeding risk was cost-effective compared to bare metal stents.

\section{Impact on daily practice}

Our study showed that, in patients at high bleeding risk, DCS were probably $(>50 \%)$ cost-saving in six different European countries, and were almost certainly ( $>98 \%)$ costeffective with a willingness to pay at $€ 10,000$ per clinical event avoided. These results are needed for the DCS price discussion in European countries.

\section{Acknowledgements}

We thank Professor Hervé Maisonneuve for his medical writing recommendations for this article.

\section{Funding}

The LEADERS FREE trial and economic evaluation were supported by Biosensors Europe.

\section{Conflict of interest statement}

I. Durand-Zaleski reports receiving personal fees from Medtronic and Boston Scientific during the conduct of the study. She is an invited speaker and undertakes educational activities at EuroPCR. K. Oldroyd reports personal fees from Biosensors, outside the submitted work. P. Urban and S. Greene are paid consultants for Biosensors. U. Windhovel is an employee of CERC and M-C. Morice is the CEO of CERC. The other authors have no conflicts of interest to declare.

\section{References}

1. Brunner-La Rocca HP, Kaiser C, Bernheim A, Zellweger MJ, Jeger R, Buser PT, Osswald S, Pfisterer M; BASKET Investigators. Cost-effectiveness of drug-eluting stents in patients at high or low risk of major cardiac events in the Basel Stent KostenEffektivitäts Trial (BASKET): an 18-month analysis. Lancet. 2007;370:1552-9.

2. Morice MC, Urban P, Greene S, Schuler G, Chevalier B. Why are we still using coronary bare-metal stents? $\mathrm{J} \mathrm{Am}$ Coll Cardiol. 2013;61:1122-3.

3. Urban P, Abizaid A, Chevalier B, Greene S, Meredith I, Morice MC, Pocock S. Rationale and design of the LEADERS 
FREE trial: A randomized double-blind comparison of the BioFreedom drug-coated stent vs the Gazelle bare metal stent in patients at high bleeding risk using a short (1 month) course of dual antiplatelet therapy. Am Heart J. 2013;165:704-9.

4. Ewen EF, Zhao L, Kolm P, Jurkovitz C, Fidan D, White HD, Gallo R, Weintraub WS. Determining the in-hospital cost of bleeding in patients undergoing percutaneous coronary intervention. J Interv Cardiol. 2009;22:266-73.

5. Kolh P, Windecker S, Alfonso F, Collet JP, Cremer J, Falk V, Filippatos G, Hamm C, Head SJ, Jüni P, Kappetein AP, Kastrati A, Knuuti J, Landmesser U, Laufer G, Neumann FJ, Richter DJ, Schauerte P, Sousa Uva M, Stefanini GG, Taggart DP, Torracca L, Valgimigli M, Wijns W, Witkowski A; European Society of Cardiology Committee for Practice Guidelines, Zamorano JL, Achenbach S, Baumgartner H, Bax JJ, Bueno H, Dean V, Deaton C, Erol Ç, Fagard R, Ferrari R, Hasdai D, Hoes AW, Kirchhof P, Knuuti J, Kolh P, Lancellotti P, Linhart A, Nihoyannopoulos P, Piepoli MF, Ponikowski P, Sirnes PA, Tamargo JL, Tendera M, Torbicki A, Wijns W, Windecker S; EACTS Clinical Guidelines Committee, Sousa Uva M, Achenbach S, Pepper J, Anyanwu A, Badimon L, Bauersachs J, Baumbach A, Beygui F, Bonaros N, De Carlo M, Deaton C, Dobrev D, Dunning J, Eeckhout E, Gielen S, Hasdai D, Kirchhof P, Luckraz H, Mahrholdt H, Montalescot G, Paparella D, Rastan AJ, Sanmartin M, Sergeant P, Silber S, Tamargo J, ten Berg J, Thiele H, van Geuns RJ, Wagner HO, Wassmann S, Wendler O, Zamorano JL; Task Force on Myocardial Revascularization of the European Society of Cardiology and the European Association for Cardio-Thoracic Surgery; European Association of Percutaneous Cardiovascular Interventions. 2014 ESC/EACTS Guidelines on myocardial revascularization: the Task Force on Myocardial Revascularization of the European Society of Cardiology (ESC) and the European Association for CardioThoracic Surgery (EACTS). Developed with the special contribution of the European Association of Percutaneous Cardiovascular Interventions (EAPCI). Eur J Cardiothorac Surg. 2014;46:517-92.

6. Levine GN, Bates ER, Blankenship JC, Bailey SR, Bittl JA, Cercek B, Chambers CE, Ellis SG, Guyton RA, Hollenberg SM, Khot UN, Lange RA, Mauri L, Mehran R, Moussa ID, Mukherjee D, Nallamothu BK, Ting HH. 2011 ACCF/AHA/SCAI Guideline for Percutaneous Coronary Intervention: executive summary: a report of the American College of Cardiology Foundation/American Heart Association Task Force on Practice Guidelines and the Society for Cardiovascular Angiography and Interventions. Circulation. 2011;124:2574-609.

7. Kirtane AJ, Gupta A, Iyengar S, Moses JW, Leon MB, Applegate R, Brodie B, Hannan E, Harjai K, Jensen LO, Park SJ, Perry R, Racz M, Saia F, Tu JV, Waksman R, Lansky AJ, Mehran R, Stone GW. Safety and efficacy of drug-eluting and bare metal stents: comprehensive meta-analysis of randomized trials and observational studies. Circulation. 2009;119:3198-206.

8. Urban P, Meredith IT, Abizaid A, Pocock SJ, Carrié D, Naber C, Lipiecki J, Richardt G, Iñiguez A, Brunel P, ValdesChavarri M, Garot P, Talwar S, Berland J, Abdellaoui M, Eberli F,
Oldroyd K, Zambahari R, Gregson J, Greene S, Stoll HP, Morice MC; LEADERS FREE Investigators. Polymer-free DrugCoated Coronary Stents in Patients at High Bleeding Risk. N Engl J Med. 2015;373:2038-47.

9. Husereau D, Drummond M, Petrou S, Carswell C, Moher D, Greenberg D, Augustovski F, Briggs AH, Mauskopf J, Loder E; ISPOR Health Economic Evaluation Publication GuidelinesCHEERS Good Reporting Practices Task Force. Consolidated Health Economic Evaluation Reporting Standards (CHEERS)-explanation and elaboration: a report of the ISPOR Health Economic Evaluation Publication Guidelines Good Reporting Practices Task Force. Value Health. 2013;16:231-50.

10. Reed SD, Anstrom KJ, Bakhai A, Briggs AH, Califf RM, Cohen DJ, Drummond MF, Glick HA, Gnanasakthy A, Hlatky MA, O'Brien BJ, Torti FM, Tsiatis AA, Willan AR, Mark DB, Schulman KA. Conducting economic evaluations alongside multinational clinical trials: toward a research consensus. Am Heart J. 2005;149:434-43.

11. van Hout BA, Serruys PW, Lemos PA, van den Brand MJ, van Es GA, Lindeboom WK, Morice MC. One year cost effectiveness of sirolimus eluting stents compared with bare metal stents in the treatment of single native de novo coronary lesions: an analysis from the RAVEL trial. Heart. 2005;91:507-12.

12. Drummond M, Barbieri M, Cook J, Glick HA, Lis J, Malik F, Reed SD, Rutten F, Sculpher M, Severens J. Transferability of economic evaluations across jurisdictions: ISPOR Good Research Practices Task Force report. Value Health. 2009;12:409-18.

13. Ong AT, Serruys PW, Mohr FW, Morice MC, Kappetein AP, Holmes DR Jr, Mack MJ, van den Brand M, Morel MA, van Es GA, Kleijne J, Koglin J, Russell ME. The SYNergy between percutaneous coronary intervention with TAXus and cardiac surgery (SYNTAX) study: design, rationale, and run-in phase. Am Heart J. 2006;151:1194-204.

14. Janssen MF, Pickard AS, Golicki D, Gudex C, Niewada M, Scalone L, Swinburn P, Busschbach J. Measurement properties of the EQ-5D-5L compared to the EQ-5D-3L across eight patient groups: a multi-country study. Qual Life Res. 2013;22:1717-27.

15. Weinstein MC, Stason WB. Foundations of cost-effectiveness analysis for health and medical practices. N Engl J Med. 1977; 296:716-21.

16. Fox J, Weisberg S. An R Companion to Applied Regression, Second Edition. Thousand Oaks, CA, USA: Sage Publications; 2011.

17. Fox J. Bootstrapping Regression Models. 2002. Available online at: avesbiodiv.mncn.csic.es/estadistica/boot1.pdf

18. R Development Core Team (2011), R: A Language and Environment for Statistical Computing. Vienna, Austria : the R Foundation for Statistical Computing. ISBN: 3-900051-07-0. Available online at: http://www.R-project.org/.

19. Wickham H. ggplot2. Cham, Switzerland: Springer International Publishing; 2016.

20. Bønaa KH, Mannsverk J, Wiseth R, Aaberge L, Myreng Y, Nygård O, Nilsen DW, Kløw NE, Uchto M, Trovik T, Bendz B, 
Stavnes S, Bjørnerheim R, Larsen AI, Slette M, Steigen T, Jakobsen OJ, Bleie Ø, Fossum E, Hanssen TA, Dahl-Eriksen Ø, Njølstad I, Rasmussen K, Wilsgaard T, Nordrehaug JE; NORSTENT Investigators. Drug-Eluting or Bare-Metal Stents for Coronary Artery Disease. N Engl J Med. 2016;375:1242-52.

21. Ong AT, Daemen J, van Hout BA, Lemos PA, Bosch JL, van Domburg RT, Serruys PW. Cost-effectiveness of the unrestricted use of sirolimus-eluting stents vs. bare metal stents at 1 and 2-year follow-up: results from the RESEARCH Registry. Eur Heart J. 2006;27:2996-3003.

22. Bakhai A, Stone GW, Mahoney E, Lavelle TA, Shi C, Berezin RH, Lahue BJ, Clark MA, Lacey MJ, Russell ME, Ellis SG, Hermiller JB, Cox DA, Cohen DJ; TAXUS-IV Investigators. Cost effectiveness of paclitaxel-eluting stents for patients undergoing percutaneous coronary revascularization: results from the TAXUS-IV Trial. J Am Coll Cardiol. 2006;48:253-61.

23. Elezi S, Dibra A, Folkerts U, Mehilli J, Heigl S, Schömig A, Kastrati A. Cost analysis from two randomized trials of sirolimus-eluting stents versus paclitaxel-eluting stents in high-risk patients with coronary artery disease. $\mathrm{J} \mathrm{Am} \mathrm{Coll} \mathrm{Cardiol.} \mathrm{2006;}$ 48:262-7.

24. Cohen DJ, Bakhai A, Shi C, Githiora L, Lavelle T, Berezin RH, Leon MB, Moses JW, Carrozza JP, Zidar JP, Kuntz RE; SIRIUS Investigators. Cost-effectiveness of sirolimus-eluting stents for treatment of complex coronary stenoses: results from the SirolimusEluting Balloon Expandable Stent in the Treatment of Patients With De Novo Native Coronary Artery Lesions (SIRIUS) trial. Circulation. 2004;110:508-14.

25. Remak E, Manson S, Hutton J, Brasseur P, Olivier E, Gershlick A. Cost-effectiveness of the Endeavor stent in de novo native coronary artery lesions updated with contemporary data. EuroIntervention. 2010;5:826-32.

26. Sculpher MJ, Pang FS, Manca A, Drummond MF, Golder S, Urdahl H, Davies LM, Eastwood A. Generalisability in economic evaluation studies in healthcare: a review and case studies. Health Technol Assess. 2004;8:iii-iv, 1-192. 